\title{
Income, Expenditure and the Living Standards of UK Households
}

\author{
RICHARD BLUNDELL and IAN PRESTON ${ }^{1}$
}

\section{INTRODUCTION}

Despite the widespread use of income as a measure of household welfare, there is much to recommend the use of consumption. Indeed, standard economic arguments suggest that consumption expenditure will better reflect expected lifetime resources and many economists have been unequivocal in advocating its use. Slesnick (1993), for example, suggests that 'From a theoretical perspective it is more appropriate to evaluate poverty using a consumption based measure of household welfare'. Cutler and Katz (1992) state that 'Economic theory suggests that permanent income or consumption is a more accurate measure of the distribution of resources than is current income'. Poterba (1989) argues that 'If households base their spending plans on their expected lifetime income, then consumption provides a more accurate measure of resources than does annual income'.

\footnotetext{
${ }^{1}$ University College London and Institute for Fiscal Studies.

The authors are grateful to James Banks, Ian Crawford, Angus Deaton, Paul Johnson, François Laisney, Costas Meghir, Sarah Tanner, Ian Walker, Steven Webb and an anonymous referee for advice and comments. This study is part of the programme of research of the ESRC Centre for the Microeconomic Analysis of Fiscal Policy at IFS. The financial support of the ESRC is gratefully acknowledged. Material from the FES made available by the CSO through the ESRC Data Archive has been used by permission of the Controller of Her Majesty's Stationery Office. The authors alone bear responsibility for the analysis and interpretation of the data reported here.
}

(C) Institute for Fiscal Studies, 1999 
This is not an issue of solely theoretical interest. For example, there have been widely referred-to and conflicting studies of household poverty that have in some cases used consumption-based measures (e.g. Commission of the European Communities, 1991) and in others income-based measures (e.g. Social Services Select Committee, 1991). Slesnick, looking at the US, argues that 'consumption based poverty rates are much lower then those based on income'. Goodman and Webb (1995), in a careful study of UK data, point out that 'there are many households throughout the population who are ranked differently by expenditure than by income'.

In this paper, we seek to understand the reasons why income and consumption can yield differing conclusions and what we can infer when income-based and consumption-based measures of inequality and poverty move differently. We argue that permanent differences in living standards will be reflected in inequality of both consumption and income. However, variation in household incomes also arises from short-run income variability. While growth in consumption inequality may be indicative of growing permanent income differences, growth in income inequality over and above this suggests an additional increase in short-term income risk.

Drawing on our earlier work (Blundell and Preston, 1994), we reach three main conclusions regarding the changing distribution of living standards in the UK over the last 20 years:

- Consumption and income measures both point to strongly-increasing inequality during the 1980 s, though the rise in income inequality over this period has been greater.

- Measures of absolute poverty based on consumption have fallen over this period.

- In the later part of the 1980 s, short-term income risk has increased alongside increased permanent inequality.

\section{MEASURING LIVING STANDARDS}

We begin by reviewing some of the issues in choosing between income and consumption. The use of income as a measure of household welfare is open to the obvious criticism that current income may not reflect the longer-run level of resources available to a household or an individual. If saving or borrowing is possible, then the household is not constrained to a consumption path that follows fluctuations in its path of incomes. Economic theories of the life cycle suggest that the household will seek to smooth its consumption stream even when its income stream is uneven. In such circumstances, we may expect consumption expenditure to better reflect the household's long-term consumption opportunities. Even where households face constraints on their 
borrowing during 'bad' periods, this does not imply that consumption will be any worse a measure of resources than income.

This basic argument offers a compelling case for preferring consumption expenditure to income but should not lead us to assume that consumption is without problems. The argument for consumption is most convincing when comparing households of similar age and similar birth year. The sort of comparisons for which we wish to use it, however, frequently involve those of different age and different birth year, and such comparisons are less appealing for a number of reasons.

Firstly, there are problems in using consumption to compare households at different stages in their lives. Life-cycle theory does not necessarily suggest a flat stream of consumption across the lifetime. The consumption of differentlyaged households may therefore differ even when their lifetime resources do not. Demographic and other influences on preferences change over the lifetime. In particular, tastes and needs can be expected to change with childbearing and child-rearing, and consumption decisions are likely to reflect this. We can seek to adjust the consumption of households at different stages in their demographic history onto a comparable basis by use of equivalence scales (see, for instance, Banks and Johnson (1994)). However, we have to recognise here that the appropriate concept is a life-cycle consistent scale, which is to say one that recognises that households adjust planned consumption streams in response to anticipated arrival of children (Banks, Blundell and Preston, 1994). Labour market status is another influence on preferences and, if some consumption expenditures reflect work-related costs (see, for example, Blundell, Browning and Meghir (1994)), a change in consumption when an individual changes his or her labour market status may not reflect any change in welfare.

Furthermore, positive real interest rates offer a financial return to delaying spending, and households that are prepared to wait ought to take advantage. Older households may have higher consumption than younger ones as a consequence. On the other hand, if households are impatient, then they will borrow against future earnings and the young may spend more than the old. Consumption reflects lifetime welfare accurately when comparing those of different ages only if these effects are absent or balance out.

Secondly, there are problems in using consumption to compare households born in very different periods. If real interest rates are variable, then comparisons of similarly-aged households in different years are rendered suspect by the difference in interest rate histories that the households will have faced. Households with similar lifetime resources but born in different years may choose different spending paths because they face different intertemporal substitution possibilities. The validity of comparisons in such a context can be shown to depend both on the extent of households' willingness to forgo consumption in one period to increase it in another and on the degree of variability in interest rates. 
These sorts of problems are all discussed at greater depth in Blundell and Preston (1994). None of these arguments offers reasons to prefer income, against which equally pertinent points could be made, but they do suggest some caution in interpreting results using consumption.

There is a further aspect to living standards that merits consideration. Much variation in income is unanticipated and this income risk makes households worse off. Families would be as well off with a lower expected income without the risk, and the amount that expected income could be reduced is a measure of the cost to them. While this cost cannot be captured by their income, the uncertainty should encourage precautionary saving which means that it will depress their consumption. The cost of increasing income risk is therefore reflected in increased precautionary saving. This offers another argument for looking sympathetically at the use of consumption.

In practice, the need to use expenditure as best available proxy for consumption introduces problems largely associated with infrequency of purchase for the more durable of consumption items. We may expect this to introduce an element in the variance of expenditure which is not a genuine reflection of variance in household living standards. However, if, as below, we place emphasis on comparison of growth in inequality and poverty for different groups rather than the cross-section level at any point in time, then, unless there has been a systematic change in the infrequency of purchase, comparisons should be unaffected. ${ }^{3}$

\section{INEQUALITY}

The data used here are drawn from the 1970-92 UK Family Expenditure Surveys; full details are given in the data appendix. In each year, we calculate measures of inequality and poverty for the whole sample but also for subsamples formed by grouping individuals according to 10-year bands for date of birth of the head of household. This allows us to follow the path of inequality and poverty within particular 'cohorts' as they pass through stages of the life cycle.

Inequality is captured using the well-known Atkinson (1970) inequality index. ${ }^{-}$Figure 1 shows the evolution of inequality calculated across the whole

\footnotetext{
${ }^{2}$ This does not mean that the amount of saving necessarily accurately captures the cost, but it is possible to be precise about the sort of attitudes to risk that would imply that it does. We have shown elsewhere that if the cost of the risk measured in this way is not affected by the household's expected income, then the saving reflects the cost exactly (Blundell and Preston, 1994).

${ }^{3}$ If anything, the growth in supermarket shopping may have led to an increase in infrequency which can only strengthen the conclusions reached below on comparisons between growth in consumption and income variances.

${ }^{4}$ The inequality aversion parameter is set equal to 0.5 . For those unfamiliar with interpretation of such parameters, this implies that an extra $£ 1$ for one household would make the same contribution to social welfare as would just over 70p to another with half its income.
} 
FIGURE 1

Atkinson Index, 1970-92

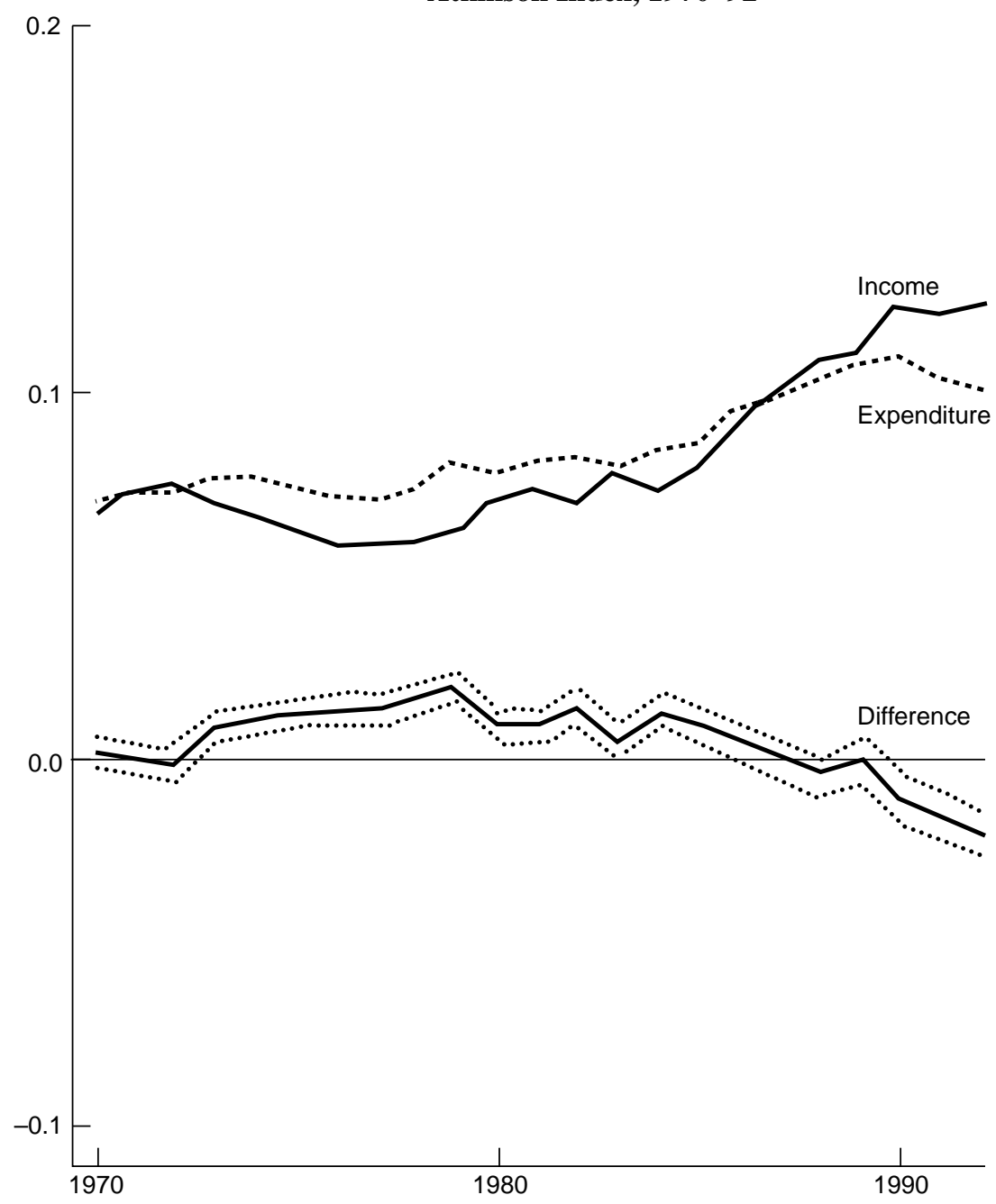

The dotted lines in this and subsequent pictures mark confidence bands of two standard errors either side of the difference. The expenditure- and income-based statistics are clearly not independent, being calculated from the same sample. Our calculation of standard errors for the differences takes account of this. We avoid putting on further confidence bands to avoid cluttering the diagram.

Source: Blundell and Preston, 1994. 
FIGURE 2

Atkinson Index within Cohort, by Year, 1970-92
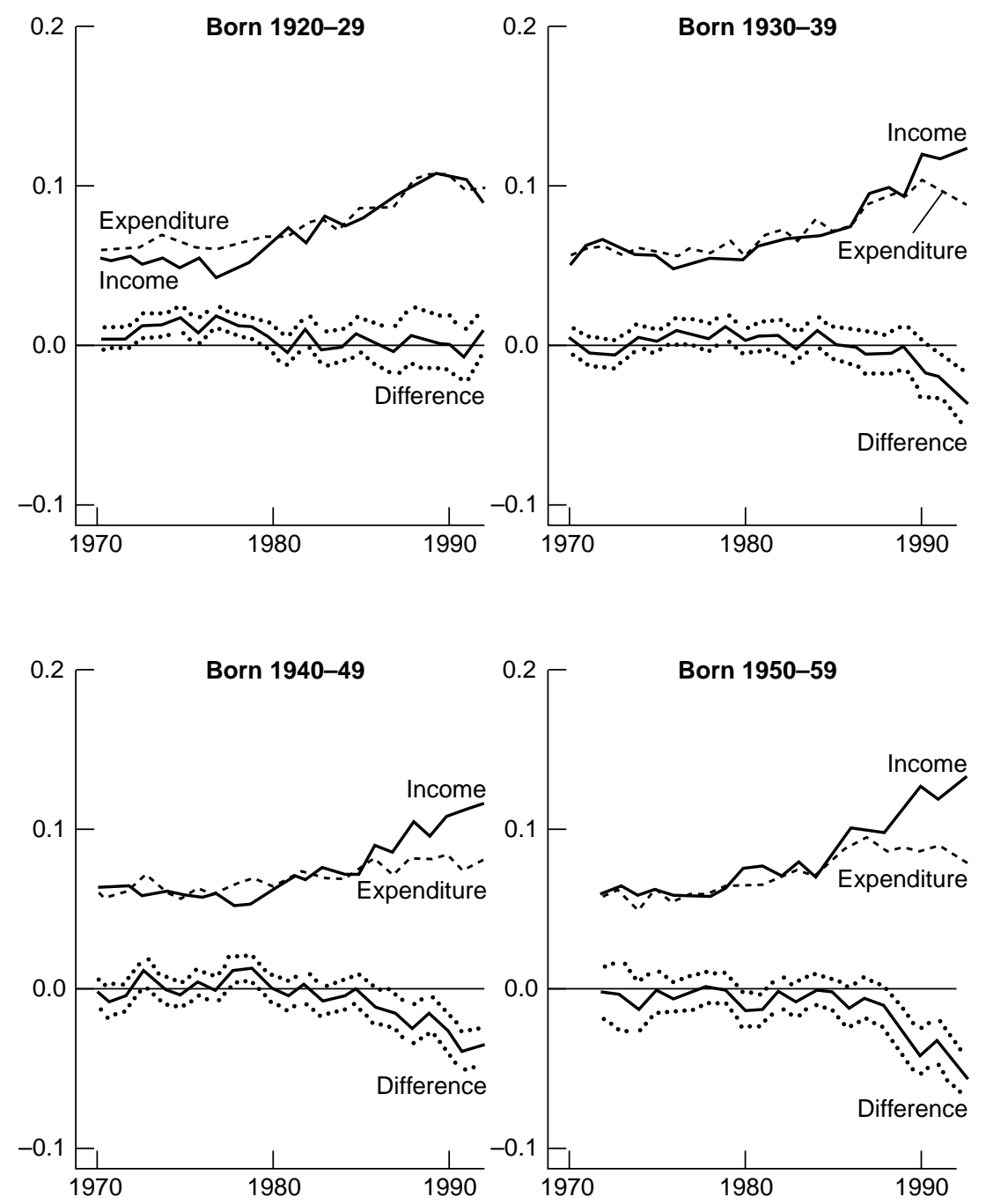

Source: Blundell and Preston, 1994. 


\section{Fiscal Studies}

sample over the whole 22-year period considered. It is clear that inequality has risen, measured in either way. Expenditure-based inequality has moved continually upward, dipping slightly only in the last few years. Income-based inequality followed a rather flatter path over the 1970s, rising steeply only in the latter half of the period. The consequence is a clearly humped path for the difference between the two measures, with income inequality rising noticeably more quickly in the 1980s. ?]

Figure 2 draws similar pictures for four date-of-birth cohorts. In each of these graphs, we are following inequality between households all of whose heads were born in similar years. For all four cohorts, we note that inequality has been rising over time, however measured. For each of the three cohorts born after 1930, we see also, as with the aggregate values, that inequality of incomes increased noticeably faster than that of expenditure, and particularly so in the 1980s. The differing picture for those born in the 1920s may be concerned with the fact that they were entering retirement during this period.

With this sort of cohort breakdown, it is also possible to compare inequality within each cohort with the level of inequality that characterised older cohorts at a similar age. To do this note that, for example, the average age in 1990 of those born in 1930-39 is roughly the same as was the average age in 1980 of those born in 1920-29. The results of making such a comparison are striking. ${ }^{6}$ Whether income or expenditure is used for measurement, all cohorts below retirement age appeared to be facing considerably greater inequality at the end of the period than had preceding cohorts at a similar age. This sort of cross-cohort comparison seems to present a very strong sense in which it can be said that inequality is increasing and that younger cohorts are facing greater inequality.

\section{POVERTY}

We measure poverty by the mean proportional shortfall from a household poverty line given by $£ 100$ per week in 1992 prices. The theoretical advantages of a shortfall index over simply counting the proportion below the line are well known (see Sen (1976)). These include sensitivity to depth of poverty of those below the line and greater robystness to choice of poverty line when distributions cross at the lower end?

\footnotetext{
${ }^{5}$ Goodman and Webb (1995) also find income inequality growing faster than expenditure inequality in the 1980s.

${ }^{6}$ For a diagrammatic presentation of such comparisons, see Blundell and Preston (1994).

${ }^{7}$ This is slightly less than half mean equivalised income and slightly more than income support entitlement (excluding housing benefit) for, say, a retired couple.

${ }^{8}$ The index takes the average across the whole population of the difference between the household's living standard and the chosen poverty line, truncating the difference from below at zero. The measure is expressed here as a proportion of the poverty line.
} 
FIGURE 3

Shortfall, 1970-92

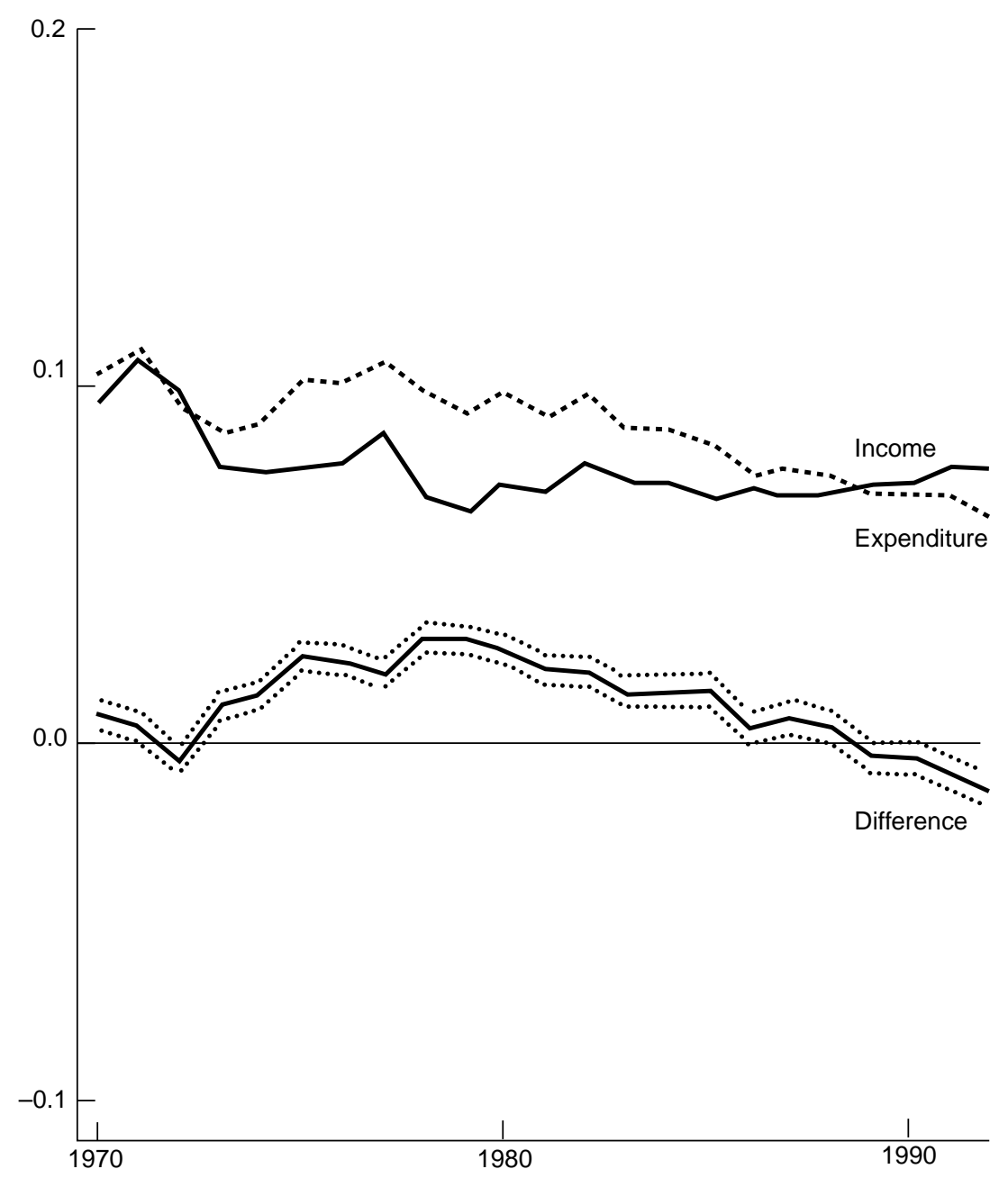

Source: Blundell and Preston, 1994.

Looking first at the measures for the whole sample as presented in Figure 3, we note that the shortfall in both incomes and expenditures has fallen but that the decline in the income shortfall was concentrated in the 1970s whereas that for expenditures by contrast came mainly in the 1980s. The consequence is a humped path for the difference between the two, as was seen to be the case with inequality. 


\section{Fiscal Studies}

\section{FIGURE 4}

Shortfall within Cohort, by Year, 1970-92
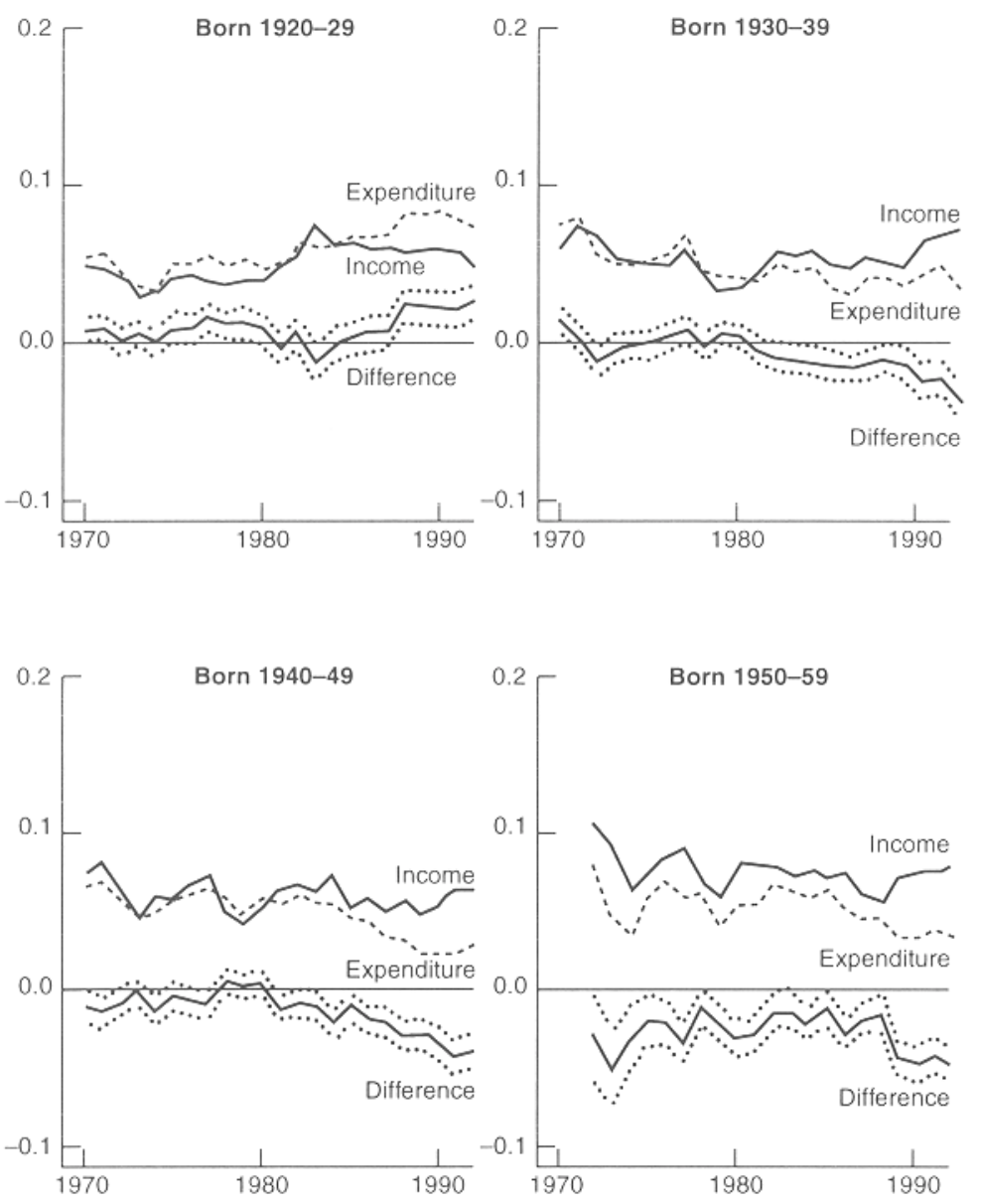

Source: Blundell and Preston, 1994. 
We can again look at individual cohorts and do so in Figure 4. The picture here is a less clear-cut one though we note that the picture of flat or declining expenditure-based poverty and flat or rising income-based poverty in the $1980 \mathrm{~s}$ does at least seem borne out by the three younger cohorts pictured. Cross-cohort comparisons also reveal an interesting divergence. For most cohorts, the incomebased shortfall at the end of the period appears higher whereas the expenditurebased shortfall appears lower than for previous cohorts at a similar age, at least for households below retirement age. []

\section{SHORT-TERM INCOME RISK AND PERMANENT INEQUALITY}

Cross-sectional variation in incomes can be generated both by permanent income differences and by short-term variability. It is important to distinguish the two. If an increase in the cross-section variance of income merely reflects an increase in uncertainty, then, as pointed out above, this will clearly have welfare costs to risk-averse consumers but it does not reflect an increase in permanent individual inequality. Uncertainty concerned with unexpected transitory shifts in income is very different from the inequality associated with permanent differences in the position of individuals in the income distribution. Growth in cross-section measures of income inequality or poverty alone cannot distinguish between these two phenomena.

We take a simple permanent income model of consumption (see Friedman (1957) and Deaton (1992)) to show how comparison of the variances of income and consumption within cohorts can help separate the causes of growing income inequality. The model developed will be crude in its treatment of savings decisions, omitting, for instance, any role for intertemporal substitution responses to interest rates or for precautionary saving, but yields general intuitions that can be shown to carry over to more general models (see Blundell and Preston (1994)). The intuition is that although the cross-section variance in income treats permanent and transitory components equally, consumption responds only to the permanent value of any income shock. As a consequence, the difference between the growth rates of income and consumption inequality is indicative of changes in short-term income risk.

To be more formal, suppose income, $y_{i t}$, of the $i$ th individual in a particular cohort in period $t$ consists of a permanent part, $y_{i t}{ }^{P}$, and a transitory part, $\varepsilon_{i t}$. The permanent part is taken to follow a process

$$
y_{i t}^{P}=y_{i t-1}^{P}+\eta_{i t}
$$

\footnotetext{
${ }^{9}$ This is most noticeable when one plots all cohorts together on a similar graph with average age along the lower axis. Such a picture can be found in Blundell and Preston (1994).
} 


\section{Fiscal Studies}

where $\eta_{i}$ is an income shock that is permanent in the sense that it is incorporated into $y_{i t}{ }^{P}$ and its effect therefore persists for all future periods.

The individual is taken to choose a consumption level, $c_{i t}$, that deviates from permanent income, $y_{i t}{ }^{P}$ (which is the expected level of its income in any future period), by a transitory consumption component $\omega_{i t}$. All three disturbance terms, $\varepsilon_{i t}, \eta_{i t}$ and $\omega_{i t}$ are assumed serially uncorrelated.

Noting that we can write the processes for income and consumption as

$$
\begin{aligned}
y_{i t} & =y_{i t}^{P}+\varepsilon_{i t} \\
& =y_{i t-1}+\eta_{i t}+\varepsilon_{i t}-\varepsilon_{i t-1} \\
c_{i t} & =y_{i t}^{P}+\omega_{i t} \\
& =c_{i t-1}+\eta_{i t}+\omega_{i t}-\omega_{i t-1}
\end{aligned}
$$

and

allows us to derive expressions for the growth in cross-section variances within the cohort. These can be shown to follow

$$
\Delta \operatorname{Var}_{t}(y)=\Delta \operatorname{Var}_{t}(\varepsilon)+\Delta \operatorname{Var}_{t}(\eta)
$$

and

$$
\Delta \operatorname{Var}_{t}(c)=\Delta \operatorname{Var}_{t}(\omega)+\Delta \operatorname{Var}_{t}(\eta)
$$

Note that if variances of the transitory components are unchanging, then variances of both income and consumption within the cohort grow with age at a similar rate due simply to cumulation of permanent shocks (see Deaton and Paxson (1994) for a similar point). Evidence of growing permanent inequality $\left(\Delta \operatorname{Var}_{t}(\eta)>0\right)$ would transpire in an acceleration rather than simply an increase of inequality within cohorts.

However, if the variances of income and consumption grow at different rates, then the difference is indicative of something that must be happening to the transitory components, since

$$
\Delta \operatorname{Var}_{t}(c)-\Delta \operatorname{Var}_{t}(y)=\Delta \operatorname{Var}_{t}(\omega)+\Delta \operatorname{Var}_{t}(\varepsilon)
$$

\footnotetext{
${ }^{10}$ Note though that this cannot explain growth over time in aggregate inequality of the sort noted in the empirical results above. The death of older cohorts and replacement by younger ones would keep the aggregate variance constant unless $\operatorname{Var}_{t}(\eta)$ were changing or the age structure of the population were shifting.
} 
FIGURE 5

Variance within Cohort, by Year, 1970-92
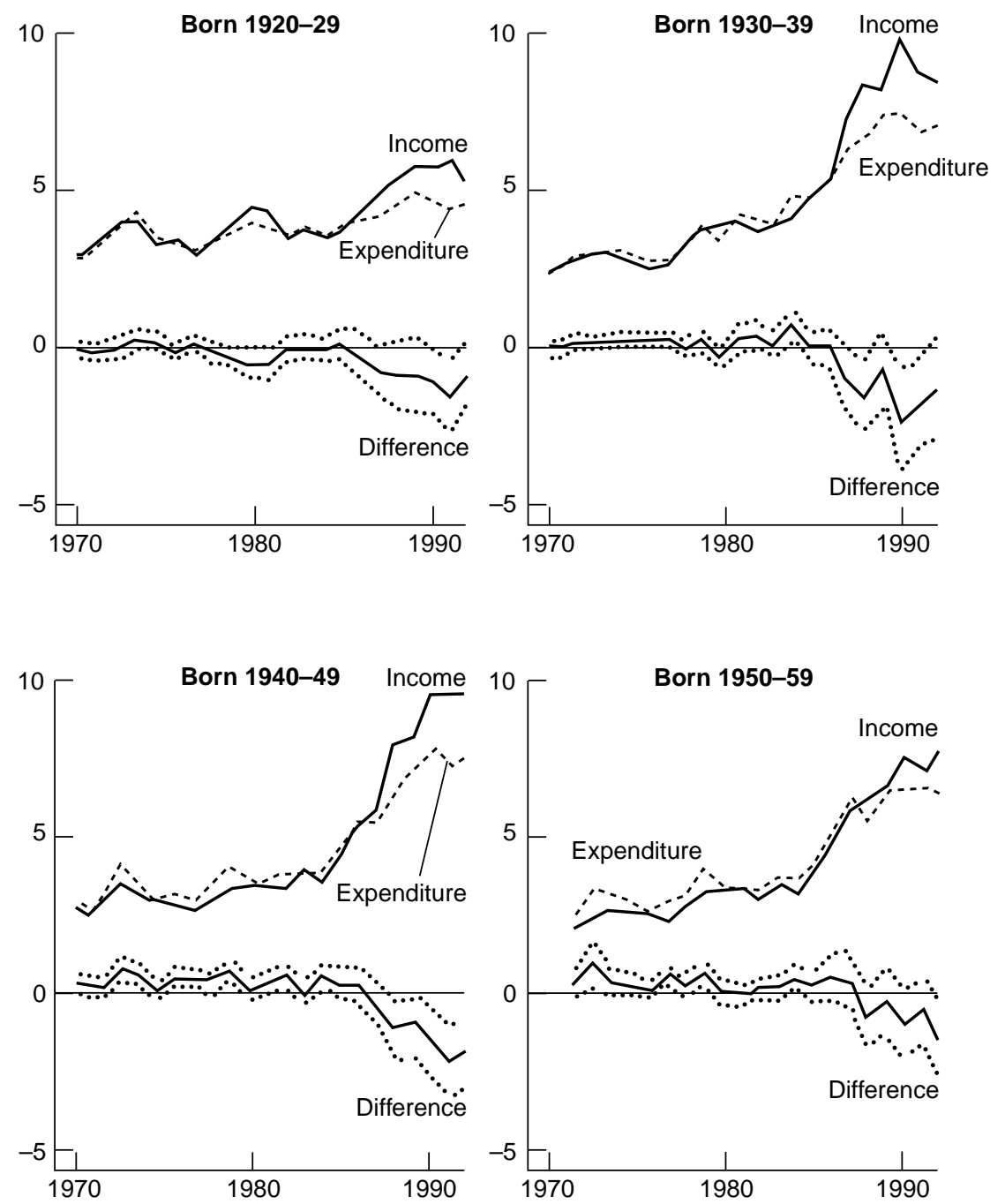

Source: Blundell and Preston, 1994. 
Assuming the variance of transitory consumption is stable $\left(\Delta \operatorname{Var}_{t}(\omega)=0\right)$, we can regard a faster growth rate in the variance of income as growing short-term income uncertainty $\left(\Delta \operatorname{Var}_{t}(\varepsilon)>0\right)$.

This is an argument of considerable intuitive appeal. If economic theories are right to suggest that consumption decisions are determined by the long-term position of the household, then permanent growth in income differences will be reflected directly in the consumption distribution in a way in which growth in short-term risk will not.

Figure 5 presents within-cohort changes over time in the variance of income and expenditure for the four date-of-birth cohorts. Within-cohort income and expenditure variances increase with age as predicted, but an acceleration in income inequality does also indeed seem to be present - there appears to be a noticeably faster rate of increase across the 1980s than across the 1970s. Using the arguments presented above, this suggests growing cross-sectional variance in permanent income shocks. Moreover, the results point, as with the Atkinson inequality measures, to a widening gap between consumption- and income-based measures towards the end of the period. This is what we argued should be expected if there is also growing short-term uncertainty in incomes alongside the growth in permanent inequality.

A distinction between short-term risk and permanent inequality is also helpful in understanding the poverty figures presented in the previous section. It may be that short-term low-income spells could be taking household incomes in younger cohorts more often below the poverty line even though their permanent shortfall, as indicated by expenditures, has been falling.

\section{CONCLUSIONS}

Inequality in both incomes and expenditures has been growing over the last 20 years. This is particularly so in the 1980 s, when income inequality was growing more rapidly than expenditure inequality. Evidence of this growth can be seen not just in the aggregate but also in individual date-of-birth cohorts, particularly those still below retirement age. We argue that the faster growth in inequality of incomes is evidence that there is both growing permanent inequality and growing short-term income risk. Furthermore, comparisons between cohorts show that younger cohorts are facing markedly greater inequality than did older cohorts at the same age. We also find, at least for younger cohorts, that whereas measures of poverty based on expenditures have typically fallen in the 1980s, measures based on incomes have changed little or risen. 


\section{DATA APPENDIX}

The data used here are from the 1970-92 UK Family Expenditure Surveys. Expenditure, for our purposes, is household expenditure on goods (including durables) other than housing. Income is household current net income net of housing costs. Expenditure and income of different family types are adjusted onto a comparable basis using the adult equivalence scales based on McClements (1977) and favoured by the UK Department of Social Security. They are expressed in 1992 pounds and the base is a childless couple. The fact that we deduct housing costs requires some justification. It makes sense in the present context for a number of reasons. For one thing, it would be necessary otherwise to construct some imputed measure of housing expenditure for owneroccupiers. One might also be uneasy as to the extent to which regional differences in housing expenditure could be taken to reflect welfare-relevant differences in the quality of housing services purchased, particularly amongst the poor (though we recognise that this is true to varying extents of other goods too). For a detailed consideration of the issues involved in treatment of housing costs, see Johnson and Webb (1991). We remove the households with the highest 10 incomes and expenditures in each year so as to enhance robustness of the results.

\section{REFERENCES}

Atkinson, A. (1970), 'On the measurement of inequality', Journal of Economic Theory, vol. 2, pp. 244-63.

Banks, J., Blundell, R. and Preston, I. (1994), 'Life-cycle expenditure allocations and the consumption costs of children', European Economic Review, vol. 38, pp. 1391-410.

Blundell, R., Browning, M. and Meghir, C. (1994), 'Consumer demand and the life-cycle allocation of household expenditures', Review of Economic Studies, vol. 61, pp. 57-80.

— and Preston, I. (1994), 'Income or consumption in the measurement of inequality and poverty', Institute for Fiscal Studies Working Paper no.94/12.

Commission of the European Communities (1991), Final Report on the Second European Poverty Programme, Brussels: Commission of the European Communities.

Cutler, D. and Katz, L. (1992), 'Rising inequality? Changes in the distribution of income and consumption in the 1980's', American Economic Review, vol. 82, pp. 546-51.

Deaton, A. (1992), Understanding Consumption, Oxford: Clarendon Press.

- and Paxson, C. (1994), 'Intertemporal choice and inequality', Journal of Political Economy, vol. 102, pp. 437-67.

Friedman, M. (1957), A Theory of the Consumption Function, Princeton: Princeton University Press.

Goodman, A. and Webb, S. (1995), The Distribution of UK Household Expenditure 1979-92, Commentary no. 49, London: Institute for Fiscal Studies.

Johnson, P. and Webb, S. (1991), UK Poverty Statistics: A Comparative Study, Commentary no. 27, London: Institute for Fiscal Studies.

McClements, L. (1977), 'Equivalence scales for children', Journal of Public Economics, vol. 8, pp. 191-210. 


\section{Fiscal Studies}

Poterba, J. (1989), 'Lifetime incidence and the distributional burden of excise taxes', American Economic Review, vol. 79, pp. 325-30.

Sen, A. (1976), 'Poverty: an ordinal approach to measurement', Econometrica, vol. 44, pp. 21931.

Slesnick, D. (1993), 'Gaining ground: poverty in the postwar United States', Journal of Political Economy, vol. 101, pp. 1-38.

Social Services Select Committee (1991), Low Income Statistics: Households Below Average Income Tables 1988, First Report 1990-91, London: HMSO. 